\title{
Processability of Cottonseed Proteins into Biodegradable Materials
}

\author{
Joël Grevellec, ${ }^{*}{ }^{\dagger}$ Catherine Marquie,${ }^{\ddagger}$ Laurent Ferry,${ }^{\dagger}$ Alain Crespy,${ }^{\dagger}$ and Viviane Vialettes ${ }^{\ddagger}$ \\ Centre des matériaux de Grande Diffusion, Ecole des Mines Ales, 6 Avenue de Clavières, 30319 Alès \\ Cédex, France; and Laboratoire des Technologies Cotonnières, CIRAD-CA, CIRAD, 2477 Avenue du Val \\ de Montferrand, B.P. 5035, 34032 Montpellier Cedex, France
}

\begin{abstract}
The manufacture of biodegradable materials from agricultural sources is a real challenge, because of environmental concerns and the need to make full use of resources. Cottonseed is an important protein source that could be used in nonfood applications, as a substitute for synthetic polymers. For the first time, the viscoelastic behavior of cottonseed protein isolate (CPI), plasticized with glycerol, was characterized in order to determine the temperature range within which cottonseed protein-based materials can be formed by extrusion or thermomolding. Research involved three main techniques: dynamic mechanical analysis to study the $\alpha$ protein relaxation associated with glass transition, as a function of plasticization by glycerol; DSC analysis to determine the effect of glycerol content on the protein denaturation and degradation temperatures; and ATG-TG/FTIR to characterize the protein degradation. The results indicated that cottonseed proteins are thermoplastics with a $T_{\mathrm{g}}$ ranging from 80 to $200{ }^{\circ} \mathrm{C}$ when the glycerol content varies from $0 \%$ to $40 \%$ (w/w, dry basis). The proteins' thermal denaturation temperature increased from 141 (without glycerol) to $195{ }^{\circ} \mathrm{C}$ in the presence of $40 \%(\mathrm{w} / \mathrm{w})$ glycerol. Protein degradation occurred at $230{ }^{\circ} \mathrm{C}$ irrespective of glycerol content, with the release of a variety of compounds. Glycerol acts as a plasticizer and thermal stabilizer of the proteins and increases the range of temperatures $\left(80-175^{\circ} \mathrm{C}\right)$ at which the material can be processed.
\end{abstract}

\section{Introduction}

The elimination of the plastic waste produced by the packaging industry is an important concern that requires the development of new solutions. The manufacture of biodegradable materials is a neat and innovative alternative to short-life petroleum-based products. However, to be competitive, biodegradable materials must achieve the same performance levels as synthetic polymers, in terms of mechanical strength, water sensitivity, and cost. This objective is the reason for investigating the potential of new resources such as cottonseed.

Until now, three main resources have been used to produce biodegradable materials: starch, proteins, and cellulose. With a worldwide production estimated at about 33 million metric tons, cottonseed is the most important source of plant proteins after soybeans. Cottonseed production, although more than double the fiber production by weight, accounts for only $15 \%$ of the commercial value of the cotton crop. Cottonseed is therefore highly attractive for nonalimentary applications such as producing a biodegradable material.

Protein-based biodegradable materials can be manufactured by two methods: wet processing technologies (casting, calendering) and low-moisture processing technologies (extrusion, injection molding).

Concerning wet technologies, many studies have explored the film-forming properties of proteins in order to make

\footnotetext{
Centre des matériaux de Grande Diffusion.

¿ Laboratoire des Technologies Cotonnières, CIRAD-CA, CIRAD.
}

edible or biodegradable films by casting processes. Higher performances are obtained either by choosing low-solubility proteins such as corn zein, ${ }^{1}$ wheat gluten, ${ }^{2}$ or myofibrillar animal proteins, ${ }^{3}$ by using cross-linking or tanning treatments, ${ }^{4}$ and/or by adding lipidic compounds. ${ }^{5}$ Cottonseed proteins, which make up $30-40 \%(\mathrm{w} / \mathrm{w})$ of the cottonseed kernel, have good film-forming properties. The fabrication of biodegradable materials from cottonseed by a casting process has been demonstrated on a laboratory scale. ${ }^{6,7}$

The casting process implies the solubilization of the proteins with stirring and heating of the solution and the evaporation of the solvent. This process takes a lot of time and energy. By comparison using low-moisture processes (extrusion, thermomolding) is probably a more appropriate strategy as they are widely used in industrial polymer processing. While there have been many scientific papers on the extrusion of proteins for food applications,${ }^{8-11}$ only a few studies have been carried out on the extrusion of proteins for nonfood applications. Redl has demonstrated the feasibility of extruding wheat gluten, plasticized with glycerol, within a narrow temperature range. ${ }^{12} \mathrm{He}$ has shown that processability is limited at low temperature by the increase in viscosity and at high temperature by cross-linking effects. Glass transition $\left(T_{\mathrm{g}}\right)$ appears to be the lower boundary of the processing range. The transition from the rigid glassy state to the viscoelastic rubbery region has been studied by several authors, either using a calorimetric approach ${ }^{13}$ or by a thermomechanical approach. ${ }^{14-16}$ Huang et al have suc- 
Table 1. IGM Water Content (\%, w/w)

\begin{tabular}{lllllll}
\hline glycerol (\%, w/w, IGM) & 0 & 5 & 10 & 20 & 30 & 40 \\
water content (\%, w/w, IGM) & 1.8 & 2.4 & 3.2 & 5.1 & 7.5 & 10.6 \\
\hline
\end{tabular}

ceeded in obtaining biodegradable plastics from soy protein and starch through extrusion and injection molding. ${ }^{8}$ They evidenced the role of denaturation during the process on the final mechanical properties of the product.

Up to now, cottonseeds have never been processed using low-moisture technologies in order to make biodegradable films. In a preliminary phase, this study focused on the thermomechanical behavior of cottonseed protein isolates in the presence of glycerol, a common protein plasticizer, to determine the temperature range in which the materials can be formed by low-moisture technologies. The viscoelastic properties of cotton proteins were studied by dynamic mechanical thermal analysis (DMTA) with the aim of assess the plasticizing effect of glycerol. The main phenomena that occur to the proteins during processing are glass transition, denaturation, and degradation. These were investigated by differential scanning calorimetry (DSC) and thermal gravimetric analysis (TGA).

\section{Experimental Section}

Materials. Preparation of Cottonseed Protein Isolate. Proteins represent $30-40 \% \mathrm{w} / \mathrm{w}$ of the cottonseed kernels and are composed of globulin (60\%), albumin (30\%), prolin $(0.5 \%)$, and glutelin $(8.5 \%) .{ }^{16}$ Cottonseed protein isolate was obtained from glandless delipidated flour after oil extraction by hexane according to the following procedure: delipidated cottonseed flour was soaked for $1 \mathrm{~h}$ in water $(10 \% \mathrm{w} / \mathrm{w})$, at $\mathrm{pH} 10$, with $5 \mathrm{~N}$ sodium hydroxide. The mixture was then centrifuged ( $10000 \mathrm{~g}, 5 \mathrm{~min}$ ), and $2 \mathrm{~N}$ hydrochloric acid was added to the supernatant to precipitate proteins at isoelectric $\mathrm{pH}$ 4.5. Protein isolate was obtained after centrifugation $(10000 \mathrm{~g}, 2 \times 5 \mathrm{~min})$, washing with cool water at $\mathrm{pH} 4.5$, and lyophilized to remove the water ( $24 \mathrm{~h}$ at $0.2 \mathrm{mbar})$. The protein content calculated after nitrogen analysis, using the conversion factor, 6.25 was $95.52 \%$ (w/w, dry matter basis).

Preparation of Cottonseed Protein Isolate/Glycerol Mixtures (IGM). Five isolate/glycerol mixtures (IGM) were prepared with $5,10,20,30$, and $40 \%$ glycerol respectively (w/w, dry matter basis). To obtain homogeneous isolate/ glycerol mixtures, the procedure described by Red ${ }^{17}$ was used: the isolate was mixed with water in order to obtain a paste. Glycerol was added and mixed with this cottonseed protein paste in a mixer. The samples were subsequently lyophilized to remove water ( $24 \mathrm{~h}$ at $0.2 \mathrm{mbar}$ ) and were finally crushed in a mortar and sieved to obtain a thin dry powder. The moisture content of each sample was determined by drying at constant weight at $105^{\circ} \mathrm{C}$. All the samples were stored in dry conditions (with $\mathrm{P}_{2} \mathrm{O}_{5}$ ) until analysis. The IGM water content is given in Table 1.

Preparation of Compression-Molded Cottonseed Protein Films for Viscoanalysis. One gram of IGM powder was placed into a film maker (P/N 15620 Graseby Specac) which consists of two platens, and a spacer ring that controls the thickness of the film. The film maker was then placed between heated platens mounted on a Graseby Specac 15 tons hydraulic press. Temperature of the platens was set using an automatic temperature controller (Graseby Specac P/N 15515). When the temperature reached $160{ }^{\circ} \mathrm{C}$, a pressure of 3 tons was applied on the sample during $5 \mathrm{~min}$. The film maker was then cooled, and a film $1 \mathrm{~mm}$ thick and $30 \mathrm{~mm}$ in diameter was obtained. Films were cut in a rectangular geometry $(1 \times 10 \times 25 \mathrm{~mm})$ for viscoanalysis.

Techniques. Dynamic Mechanical Analysis. Measurements were carried out with a Metravib Instrument viscoanalyzer (Limonest, France). A variable-amplitude, sinusoidal mechanical stress was applied to the sample (frequency $=5$ $\mathrm{Hz}$ ) to produce a sinusoidal strain of pre-selected amplitude (50 $\mu \mathrm{m}$ chosen in the linearity zone of the material). The traction compression mode was chosen. Temperature scans (from 25 to $230{ }^{\circ} \mathrm{C}$ ) were performed at a heating rate of 5 ${ }^{\circ} \mathrm{C} / \mathrm{min}$. For each formulation, three samples were tested. During analysis, the stored values were the storage modulus ( $E^{\prime}=$ dynamic elastic Young's modulus), the loss modulus $\left(E^{\prime \prime}\right)$, and the loss tangent $(\tan \delta)$. Location of the $\alpha$-relaxation temperature was determined from the maximum of the $\tan \delta$ peak. The $\alpha$-relaxation temperature was considered to be equivalent to (assimilated as) the glass transition temperature $\left(T_{\mathrm{g}}\right)$.

Differential Scanning Calorimetry (DSC). Differential scanning calorimetry measurements were carried out using a DSC 92 Setaram apparatus (Caluire, France). The heating rate was $5{ }^{\circ} \mathrm{C} / \mathrm{min}$ and the scanning temperature ranged from 25 to $180^{\circ} \mathrm{C}$. The IGMs were packed down and sealed into aluminum DSC pans with inverted lids to achieve optimum thermal conductivity. The heat flow was recorded for each sample. The reversibility of each phenomenon was checked by a second DSC scan within its temperature range.

Thermogravimetric Analysis (TGA). Analyses were carried out using a ATD-TG (TGA92 Setaram, Caluire, France) coupled with a Fourier transform infrared spectrometer (Bruker IFS 66, Wissembourg, France). IGM samples were heated from 30 to $600{ }^{\circ} \mathrm{C}$ at $5{ }^{\circ} \mathrm{C} / \mathrm{min}$ in an argon atmosphere. Infrared spectra were recorded between 450 and $5000 \mathrm{~cm}^{-1}$ every $5 \mathrm{~s}$ and were integrated according to the following Gram-Schmidt treatments: a Gram-Schmidt integration corresponding to the whole infrared spectrum; a Gram-Schmidt integration corresponding to the hydrazine spectrum (975 to $900 \mathrm{~cm}^{-1}$ ); a Gram-Schmidt integration corresponding to the water spectrum (1900 to $1200 \mathrm{~cm}^{-1}$ ).

It was not possible to perform a Gram-Schmidt integration for glycerol because the glycerol signal was covered by baseline noise.

Particular calculations were made in order to explain the following: protein degradation in the presence of glycerol; glycerol evaporation from the IGM sample in comparison with isolate.

First, all the curves giving the mass loss as a function of temperature were recalculated for different IGM samples to obtain $0 \%$ mass loss at $100{ }^{\circ} \mathrm{C}$, corresponding to the evaporation of water. Second, theoretical curves giving the mass loss as a function of temperature for IGM $30 \%$ and $40 \%(\mathrm{w} / \mathrm{w})$ of glycerol were recalculated after adding the lost mass of glycerol multiplied by 0.3 and 0.4 , respectively, 


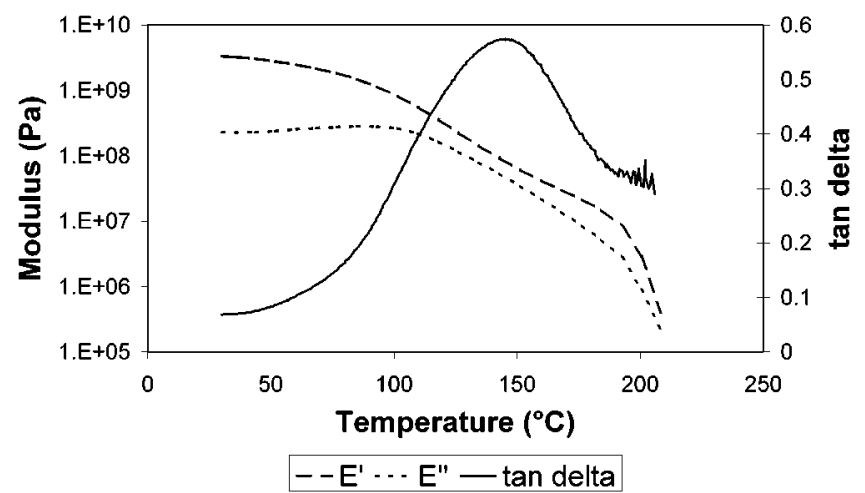

Figure 1. Viscoanalyzer analysis of cottonseed protein isolate (IGM) plasticized with $10 \%(\mathrm{w} / \mathrm{w}$, dry basis) glycerol.

to the lost mass of isolate multiplied by 0.7 and 0.6 , respectively.

\section{Results}

Viscoelastic Properties of Cottonseed Proteins Plasticized by Glycerol. Figure 1 shows plots of the storage modulus $E^{\prime}$ and $\tan \delta$ vs temperature for an IGM containing $10 \%$ (w/w, dry basis) glycerol. Cottonseed proteins clearly display the typical behavior of an amorphous polymer: with increasing temperature, these proteins go through the glassy region, the transition region ( $\tan \delta$ peak and $E^{\prime}$ modulus drop), and a small rubbery plateau followed by a flow region.

Cotton proteins exhibit a wide transition region (about 150 ${ }^{\circ} \mathrm{C}$ ). This feature is commonly observed for heterogeneous biopolymers, ${ }^{17}$ In this case it may be due to the presence of protein subunits of different molecular weights (from 20000 to 300000 ), in a wide variety of degrees of order, and nonproteinic molecules that were not removed during the isolate preparation.

Cottonseed proteins show two fall steps in the storage modulus. The first fall in storage modulus $\left(E^{\prime}\right)$, from $5 \times$ $10^{9}$ to $1 \times 10^{7} \mathrm{~Pa}$, is associated with the $\alpha$ relaxation and is similar to synthetic polymers (from $10^{9.5}$ to $10^{6.5} \mathrm{~Pa}$ ) according to Kalichevsky et al. (1993).$^{18}$ It is then followed by a very small rubbery plateau and a flow rate region (second fall step) which both characterize a polymer without cross-linked and tangled chains. This type of behavior ( $\alpha$ relaxation and a flow rate region) is characteristic of thermoplastic materials.

The temperature of the main relaxation $T_{\alpha}$ associated with the glass transition $T_{\mathrm{g}}$ was reported as a function of the glycerol content in IGM in Figure 2. The plasticizing effect of glycerol is clearly indicated by a decrease in the $T_{\alpha}$ from 202 to $82{ }^{\circ} \mathrm{C}$ with increasing glycerol content. This behavior, characterized by a high $T_{\alpha}$ for dry proteins and a regular decrease in $T_{\alpha}$ with increasing plasticizer content, has already been observed in many biopolymer systems such as polysaccharides and proteins. ${ }^{17,19-21}$

Compression-molding tests were carried out to obtain films, providing another means of examining the viscoelastic properties of IGM. These experiments showed that film can be processed above temperatures varying from $80{ }^{\circ} \mathrm{C}$ for $40 \%$ IGM, to $160{ }^{\circ} \mathrm{C}$ for isolate. These results underline the thermoplastic properties of cottonseed proteins, and the

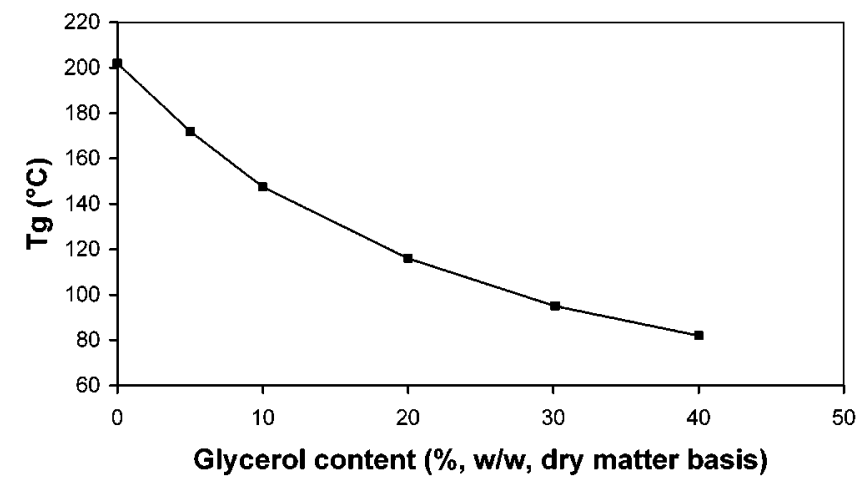

Figure 2. Glass transition temperature $\left(T_{\mathrm{g}}\right)$ of cottonseed proteins as a function of glycerol content (\%, w/w, dry matter basis). $T_{\mathrm{g}}$ was determined from $\alpha$ transition analyzed with viscoanalyzer.

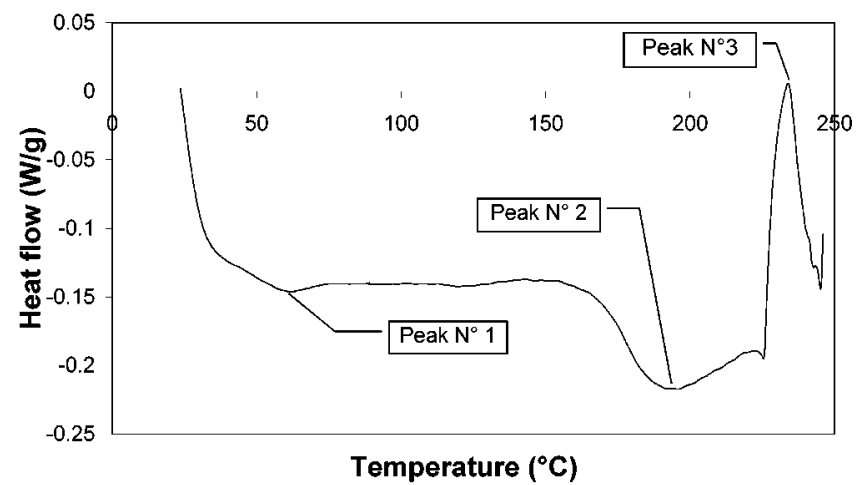

Figure 3. Typical DSC heat flow signal for cottonseed protein isolate plasticized with glycerol (40\%, w/w, dry matter basis).

plasticizing effect of glycerol. Compression molding of IGM confirms that $T_{\alpha}$ defines the lower boundary of the processing range. We also observed that plasticization widens the processing range, since $40 \%$ IGM films can be obtained from 80 to $180{ }^{\circ} \mathrm{C}$ whereas isolate films can only be produced between 160 and $180{ }^{\circ} \mathrm{C}$.

Thermal Denaturation and Degradation of Cottonseed Proteins Plasticized by Glycerol. The thermal denaturation of cottonseed proteins was studied by DSC. A typical heat flow curve for an IGM is given in Figure 3. The method is not sensitive enough to identify the glass transition of cottonseed proteins. However, we observe two irreversible endothermic phenomena occurring at 63 (peak 1) and 195 ${ }^{\circ} \mathrm{C}$ (peak 2), and a third irreversible exothermal peak at 234 ${ }^{\circ} \mathrm{C}$ (peak 3). Peaks 1 and 2 may be due to protein denaturation and peak 3 to degradation. The absence of a fusion peak indicate that cottonseed protein isolate adopts an amorphous structure, as confirmed by the WAXS spectrum (Figure 4).

Figure 5 gives a comparison between heat flows obtained for IGMs with different glycerol contents (\%,w/w). The first peak is not affected by the glycerol content. Peak 2, located at $141{ }^{\circ} \mathrm{C}$ for isolate (without glycerol), moves toward higher temperatures and decreases in a magnitude as the glycerol content in IGM increases because this happens at the same time as water and glycerol departures. It is well-known today that many proteins are stabilized against thermal denaturation by polyols. 22,23 Thermodynamic studies have shown that glycerol acting as a cosolvent (in the presence of water) may affect the physical stability of proteins. ${ }^{24}$ The mechanism is preferential hydration of the protein, which is defined as the 


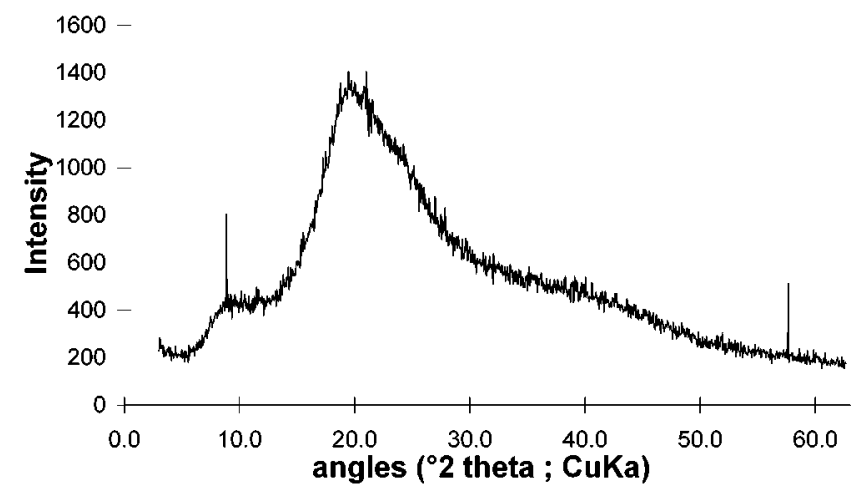

Figure 4. WAXS analysis made on cottonseed isolate powder.

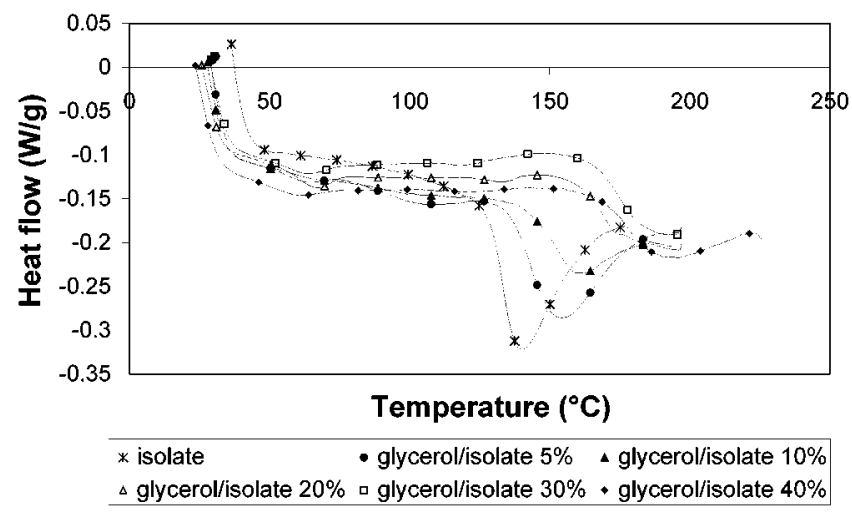

Figure 5. DSC total heat flow signals for protein cottonseed isolate plasticized with glycerol $(0,5,10,20,30$, and $40 \%, w / w$, dry basis).

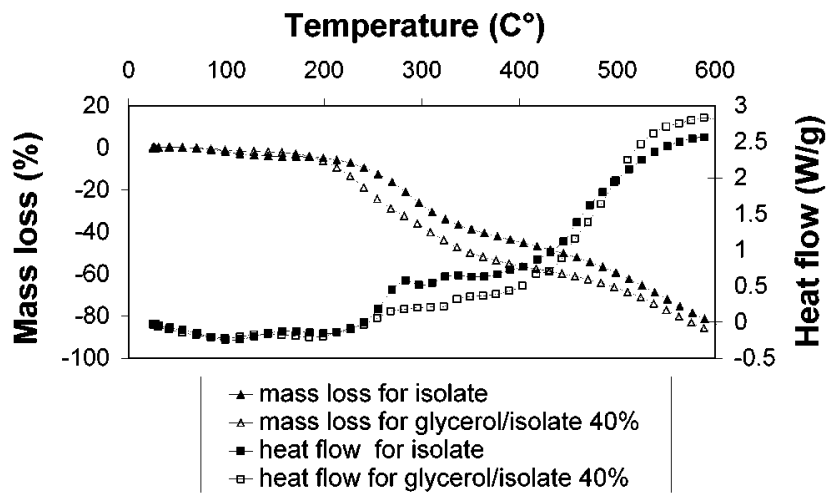

Figure 6. Analysis of thermal degradation of cottonseed protein isolate by ATD-TG.

exclusion of the cosolvent from the protein surface as the result of an increase in the surface tension of the water. The protein does not interact with the cosolvent and becomes fully hydrated, surrounded by a cosolvent-free layer of water. The application of cosolvents, which causes preferential hydration of the protein, stabilizes compact protein conformations because addition of cosolvent results in an increase in the free energy of the system.

Thermal degradation of cottonseed proteins was studied by ATD-TG/FTIR. Figure 6 shows the evolution of the weight loss of isolate as a function of temperature. We observe an initial loss of mass (about $3 \%$ ) occurring at 85 ${ }^{\circ} \mathrm{C}$ corresponding to an endothermic heat flow and ascribed by infrared analysis to a loss of residual water. A second loss of mass occurring at $200{ }^{\circ} \mathrm{C}$ and a third at $460{ }^{\circ} \mathrm{C}$ can be identified as corresponding to the exothermic degradation

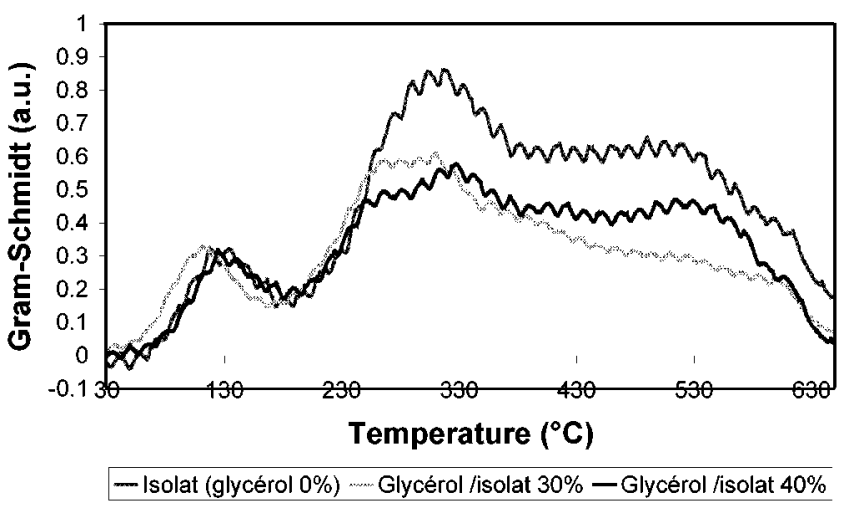

Figure 7. Water spectrum Gram-Schmidt integration. Analysis of the water lost mass as a function of temperature for isolate and IGM plasticized with 30 and $40 \%$ (w/w, dry matter basis) of glycerol.

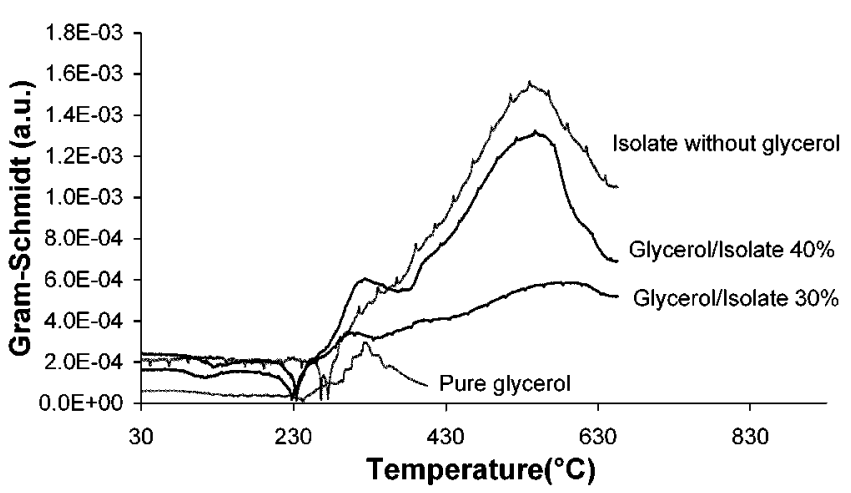

Figure 8. Generalized Gram-Schmidt analysis of the glycerol loss mass as a function of temperature for glycerol alone, isolate without glycerol and IGM plasticized with 30 and $40 \%$ (w/w, dry matter basis) of glycerol, respectively.

and carbonization of proteins, respectively. When isolate is plasticized with glycerol, a new loss of mass occurs at 175 ${ }^{\circ} \mathrm{C}$.

The Gram-Schmidt integration calculated with the water spectrum (Figure 7) indicated two types of water loss: one between 70 and $180{ }^{\circ} \mathrm{C}$, which corresponds to the hydration water and a second, occurring between 180 and $550{ }^{\circ} \mathrm{C}$, which stems from protein degradation and combustion. This emission increased with the protein content in the sample.

The superposition of generalized Gram-Schmidt integration identified the product released at $175{ }^{\circ} \mathrm{C}$ as glycerol (Figure 8). Indeed, on the glycerol, IGM $30 \%$ glycerol, and IGM $40 \%$ glycerol curves a peak is observed that does not appear for the isolate.

Among the diverse products released during protein degradation, hydrazine $\left(\mathrm{NH}_{2}-\mathrm{NH}_{2}\right)$ was easily identified by infrared analysis, with an increasing signal from 230 to 410 ${ }^{\circ} \mathrm{C}$.

The Gram-Schmidt integration calculated for the hydrazine spectrum is given in Figure 9. The increasing emission of hydrazine with increasing protein content of samples, combined with a significant loss of mass, confirms the occurrence of protein degradation in the $230-420{ }^{\circ} \mathrm{C}$ temperature zone.

To analyze the effect of glycerol on protein degradation we compared the theoretical (calculated) weight loss of glycerol in plasticized IGM to the weight loss of pure glycerol (Figure 10). The theoretical weight loss for IGM is 


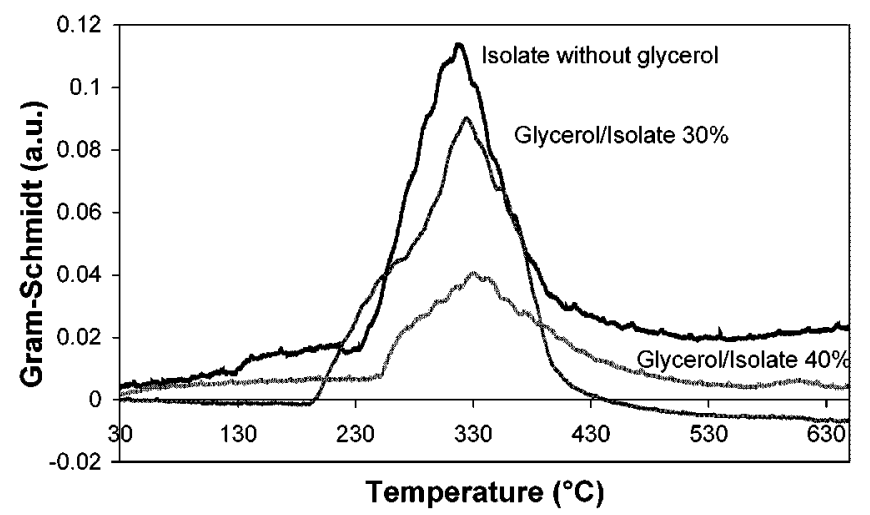

Figure 9. Hydrazine spectrum Gram-Schmidt integration. Analysis of the hydrazine loss mass as a function of temperature for isolate and IGM plasticized with 30 and $40 \%$ (w/w, dry matter basis) of glycerol.

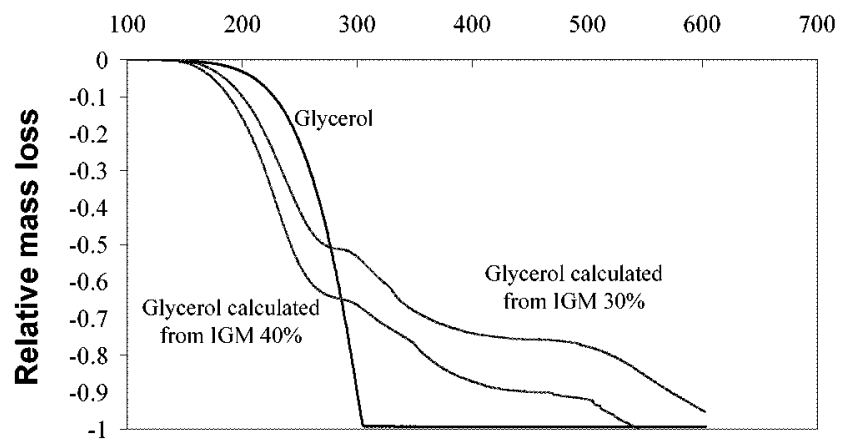

Temperature $\left({ }^{\circ} \mathrm{C}\right)$

Figure 10. Mass loss of glycerol as a function of temperature. Comparison with theoretical curves obtained by calculation for IGM 30 and $40 \%$ of glycerol.

taken as the addition of the mass losses for pure glycerol and pure isolate (which means considering that there is no interaction between these two components).

(weight loss for IGM 40\%) $=0.4 \times$

(weight loss of glycerol in IGM 40\%) $+0.6 \times$

(weight loss for isolate)

We then deduce the equation used to calculate the weight loss of glycerol for IGM: (weight loss of glycerol in IGM 40\% calculated $)=[$

(weight loss for IGM 40\%) $-0.6 \times$

(weight loss for isolate)]/0.4

The glycerol evaporation occurred at a lower temperature (mass loss of $1.5 \%$ at $165^{\circ} \mathrm{C}$ ) when mixed with isolate than when it was alone (mass loss of $1.5 \%$ at $183{ }^{\circ} \mathrm{C}$ ). This phenomenon has already been observed by Di Gioia ${ }^{25}$ with maize gluten. In addition, it was noted that in the presence of isolate glycerol is released in three steps, whereas only one step was observed for pure glycerol. The pure glycerol is completely evaporated at $300{ }^{\circ} \mathrm{C}$ whereas only $53 \%$ of glycerol for IGM $30 \%$ glycerol and $66 \%$ of glycerol for IGM $40 \%$ glycerol were released at the same temperature. For both plasticized IGM curves, we also observe a plateau indicating that some glycerol is present in the proteins up to their combustion. These results support the hypothesis that mixing glycerol with cottonseed protein isolate (IGM) gives two types of interaction with proteins: a low bounded glycerol, which evaporates at a lower boiling point than pure glycerol (interactions glycerol-proteins < interactions glycerol-glycerol); and a strong bounded glycerol, giving higher interactions with proteins than with glycerol molecules. In this case, we can assume that glycerol is trapped inside the protein core.

\section{Conclusion}

As a conclusion it appears that cottonseed proteins behave like thermoplastic macromolecules and are thus amenable to being processed by low-moisture technologies. According to mechanical and thermal analysis, glycerol has two main effects on the properties of cottonseed proteins. On one hand, it acts as a plasticizer: in other words an increase in the glycerol content of the IGM leads to a lower $\alpha$-relaxation temperature, as observed by DMTA. On the other hand, DSC showed that cottonseed proteins became more stable with regard to thermal denaturation when mixed with an increased proportion of glycerol. This phenomenon could be explained by a cosolvent effect of glycerol corresponding to preferential hydration of proteins entailing a stabilization of folded conformations.

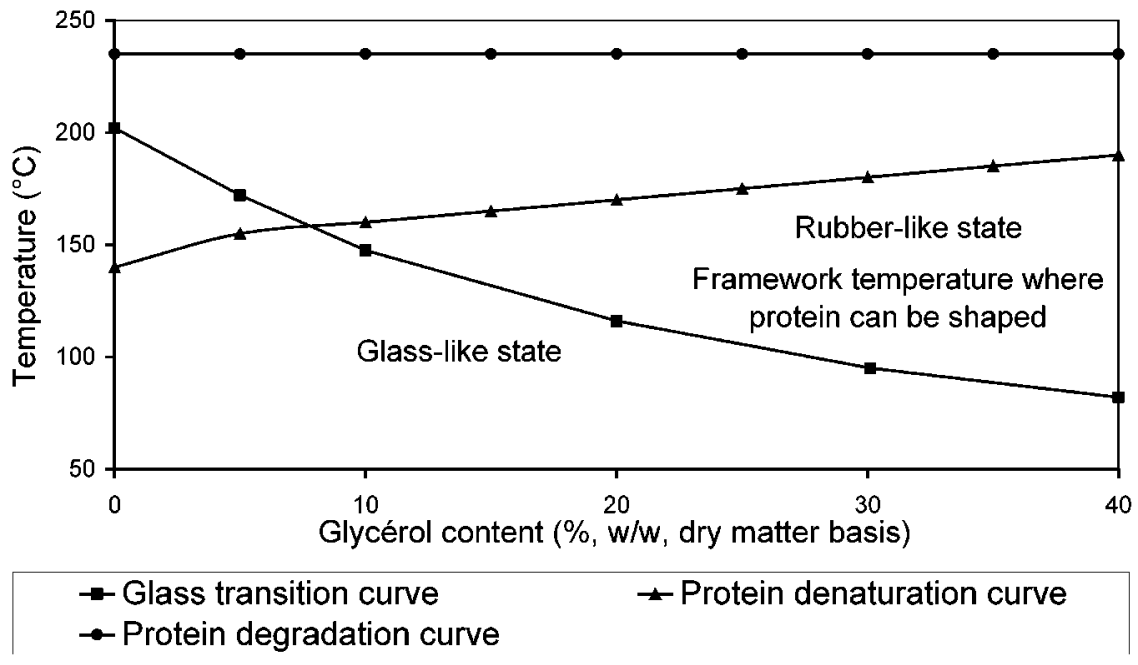

Figure 11. General thermal behavior of cottonseed protein plasticized with glycerol. 
In addition, IR and thermal analyses gave us a better understanding of the general thermal behavior of cottonseed proteins and IGMs. When heated, cottonseed proteins undergo a two-step denaturation before degrading, with the release of water and hydrazine. Moreover ATG-TD/FTIR revealed the presence of two different glycerol-protein interactions, leading to a partial loss of glycerol at $175^{\circ} \mathrm{C}$, while the remaining glycerol stays in IGM until the degradation takes place.

Because of its effect on the glass transition and denaturation temperatures, glycerol broadens the working range for the thermoprocessing of cottonseed proteins (Figure 11). For $40 \%$ IGM, the denaturation temperature $\left(195^{\circ} \mathrm{C}\right)$ is even higher than the glass transition temperature $\left(80^{\circ} \mathrm{C}\right)$, whereas for the isolate $T_{\mathrm{g}}$ is higher than the denaturation temperature, and it is therefore necessary to denature the proteins before a homogeneous material can be formed. The study covered in this paper is an initial step before the analysis of more complex materials like cottonseed flour or cakes.

\section{References and Notes}

(1) Park, H. J.; Chinnan, M. S.; Shewfelt, R. L. Edible corn zein coating to extend storage life of tomatoes. J. Food Process. Preserv. 1994, 18, 317-331.

(2) Gennadios, A.; Weller, C. L. Edible film and coating from wheat and corn proteins. Food Technol. 1990, 10, 63-69.

(3) Cuq, B.; Aymard, C.; Cuq, J. L.; Guilbert, S. Edible packaging films based on fish myofibrillar proteins: formulation and functional properties. J. Food Sci. 1995, 60, 1369-1347.

(4) Marquié, C.; Tessier, A. M.; Aymard, C.; Guilbert, S. HPLC determination of the reactive lysine content of cottonseed protein films to monitor the extent extend of cross-linking by formaldehyde, glutaraldehyde and N-glyoxal. J. Agric. Food Chem. 1997, 45, 922926 .

(5) Kamper, S. L.; Fennema, O. Water vapor permeability of edible bilayer films. J. Food Sci. 1984, 49, 1482-1485.

(6) Marquié, C.; Aymard, C.; Cuq, J. L.; Guilbert, S. Biodegradable packaging made from cottonseed flour: formation of improvement by chemical treatment with gossypol, formaldehyde and glutaraldehyde. J. Agric. Food Chem. 1995, 43, 2762-2766.

(7) Marquié, C.; Héquet, E.; Tessier, A. M.; Vialettes, V. Fabrication d'emballages et de films biodegradables à partir de farines de coton. Ol., Corps Gras, Lipides 1996, 3, 352-356.

(8) Huang, S.; Liang, M.; Lardy, G.; Huff, H. E.; Kerley, M. S.; Hsieh, F. Extrusion processing of rapeseed meal for reducing glucosinolates. Anim. Feed Sci. Technol. 1995, 56, 1-9.

(9) Chouldhury, G. S.; Gautam, A. Comparative study of mixing elements during twin-screw extrusion of rice flour. Food Res. Int. 1998, 31, $7-17$.
(10) Strecker, T. D.; Cavalieri, R. P.; Pomeranz, Y. Wheat gluten and glutenin thermal conductivity and diffusivity at extruder temperatures. J. Food Sci. 1994, 59, 1244-1250.

(11) Batterman-Azcona, S. J.; Lawton, J. W.; Hamaker, B. R. Microstructural changes in zein proteins during extrusion. Scanning 1999 $21,212-216$.

(12) Redl, A.; Morel, M. H.; Bonicel, J.; Vergnes, B.; Guilbert, S. Extrusion of wheat gluten plasticized with glycerol: Influence of process conditions on flow behaviour, rheological properties and molecular size distribution. Cer. Chem. 1999, 76, 361-370.

(13) Noel, T. R.; Parker, R.; Ring, S. G.; Tatham, A. S. The glass-transition behaviour of wheat gluten proteins. Int. J. Biol. Macromol. 1995, $17,81-85$.

(14) Kalichevsky, M. T.; Blanchard, J.; Marsh, R. D. L. Application of mechanical spectroscopy to the study of glassy biopolymers and related systems. In The Glassy State in Foods; Blanchard, J. M. V., Lillford P. J., Eds.; Nottingham University Press: Loughborough, England, 1993; pp 133-156.

(15) Wetton, R. E. Dynamic mechanical thermal analysis of polymers and related systems. In Developments in Polymer Characterization; Dawkins, J. V., Ed.; Elsevier Applied Science Publishers: Amsterdam, 1986; Vol. 5, pp 179-221.

(16) Saroso, B. Chemical properties of proteins in cottonseed kernels. Ind. Crop. Res. J. 1989, 1, 60-65.

(17) Redl, A.; Pouplin, M.; Gontard, N. Glass transition of wheat gluten proteins as a function of water, glycerol and sorbitol content. J. Agric. Food Chem. 1999, 47, 538-543.

(18) Kalichevsky, M. T.; Blanchard, J.; Tokarczuk, P. Effect of water content and sugars on the glass transition of casein and sodium caseinate. Int. J. Food Sci. Technol. 1993, 28, 139-151.

(19) Kalichevsky, M. T.; Jaroszkiewicz, E. M.; Blanchard, J. M. V. Glass transition of gluten. 1: gluten and gluten-sugar mixtures. Int. J. Biol. Macromol. 1992, 14, 257-266.

(20) Roos, Y. H.; Karel, H. Water and molecular weight effect on glass transition in amorphous carbohydrate solutions. J. Food Sci. 1991, 56, 1676-1681.

(21) Cuq, B.; Gontard, N.; Guilbert, S. Thermoplastic properties of fish myofibrillar proteins: application to biopackaging fabrication. Polymer 1997, 38, 4071-4078.

(22) Moriyama, S.; Matsuno, R.; Kamikubo, T. Influence of dielectric constants and ligand binding on thermostability of glucoamylase. Agric. Biol. Chem. 1977, 41, 1985-1993.

(23) Otamiri, M.; Adlercreutz, P.; Mattiasson, B. A differential scanning calorimetric study of Chymotrypsin in the presence of added polymers. Biotechnol. Bioeng. 1994, 44, 73-78.

(24) Cleland, J. L.; Powell, M. F.; Shire, S. J. The development of a stable protein formulation: a close look at protein aggregation, deamidation and oxidation. Crit. Rev. Therap. Drug Carrier Syst. 1993, 10, 307377.

(25) Di Gioia, L.; Guilbert, S. Corn protein-based thermoplastic resins: effect of some polar and amphiphilic plasticizers. J. Agric. Food. Chem. 1999, 47, 1254-1261. 